\title{
Reflections on the history of Indigenous people's struggle for human rights in Australia - What role could a treaty play?
}

\author{
William Jonas
}

Let me first make two points about the history of the rights of Indigenous people in this country.

First, Indigenous peoples' struggle for recognition of their human rights remains to a large extent unfulfilled. Consequently, the struggle is not, and has never been, well reflected in Australian law. Second, human rights continue to be poorly and rather patchily implemented in our legal system. A focus on human rights in Australian law would therefore leave us missing at least half the story of the struggle for recognition by Indigenous peoples in this country.

Accordingly, I intend to provide an overview of Indigenous people's struggle for recognition of their human rights, noting some of the significant gains that have been made to date as well as restrictions on the exercise of rights. I will conclude with some observations about where we are currently at, the problems we continue to face and how a treaty could assist us to provide the just settlement that continues to elude Indigenous peoples.

Aborigines and Torres Strait Islanders - the Indigenous peoples of this country - have fought for the recognition of their human rights since the beginning of European settlement. We could look to the efforts of every generation of Indigenous peoples and we would find resistance and the assertion of rights - though earlier generations would not have referred to them as 'rights'.

Over the course of the nineteenth century, Indigenous peoples faced decimation of their populations through warfare, disease and dislocation, and the slow but sure dispossession from their lands as the white man's frontier expanded 'on the sheep's back' as Geoffrey Blainey once put it. Yet there was no negotiation with Indigenous peoples about the taking of their land. There was no compensation. The colonisation process was one based on the belief of racial superiority over Indigenous peoples. This was manifested through the assertion of terra nullius - that Indigenous peoples were so low in the social scale as to not have systems of government, property, law and culture that could be recognised. Instead, this land was deemed to be empty - land belonging to no one.

The injustice of this history, and the illegitimacy of this process, has only just begun to be recognised for what it is in recent years. The foundational myth of peaceful, consensual settlement has created what the Aboriginal Provincial Government refers to as a lack of 'moral legitimacy' of the assertion of sovereignty over Indigenous peoples. 
By the end of the nineteenth century there had emerged some key themes in the treatment of Indigenous peoples - first, that our numbers were so reduced that we were seen to be a 'dying race', with policies very much oriented towards facilitating this eventuality by 'smoothing the dying pillow'. This approach was implemented largely through a system of segregation of Aboriginal people to reserves and progressively into the twentieth century through attempts at assimilation through the separation of Indigenous children of mixed descent from their families. This was accompanied by the most extraordinary levels of regulation and control over the lives and movement of Indigenous peoples. And this regulation by governments led to an almost total denial of the citizenship rights of Indigenous peoples.

This is very much the situation as it existed at federation in 1900. The federal Constitution of 1900 contained only two references to Indigenous peoples - both of which excluded Indigenous people. Section 127 provided that in the reckoning of the numbers of the Commonwealth 'aboriginal natives shall not be counted', whereas s. 51(26) - the so-called 'races power' provided the federal Parliament with the ability to make laws with respect to 'the people of any race, other than the Aboriginal race in any State, for whom it is deemed necessary to make special laws'.

There is a perception that because of these provisions the Constitution in fact operated to exclude Indigenous peoples from citizenship in Australia. This is, however, a fallacy. As John Chesterman and Brian Galligan note in their excellent study of Indigenous citizenship in Australia which is titled Citizens without rights:

The exclusion of Aborigines from citizenship was by no means a constitutionally ordained necessity, but rather a deliberate product of Commonwealth and State government legislation and administration. The exclusionary category of 'aboriginal native' was central to the institutional definition and development of Australian citizenship, and was created by the legislature, defended to a certain extent by the judiciary, and most importantly, developed, nurtured and administered by the bureaucracy for over sixty years. Far from being a product of a rigid constitution, conceived and endorsed by nineteenth century colonial racists, the long exclusion of Aboriginal Australians from Australian citizenship was implemented and routinely administered by Australian governments and bureaucracy until well into the second half of the twentieth century. ${ }^{1}$

In this sense the Constitution cannot be seen as a taker of rights - it is not the Constitution, for example, that excluded many Indigenous people from voting or that imposed strict regulation of employment. That instead was the result of a complex web of state and territory laws, regulations and ordinances.

But the Constitution can also not be seen as a protector of rights. Chief Justice Malcolm has written in this volume about the absence of a Bill of Rights in Australia. Many people also often cite the absence of a power for the Commonwealth to make special laws for Aboriginal peoples as problematic in this regard.

${ }^{1}$ Chesterman and Galligan 1998: 84. 
And there are many examples in the following fifty years which demonstrate that the federal government would use the express limitation of the races power in s.51(26) as a basis for not extending many basic citizenship entitlements to Indigenous peoples. It was, of course, an erroneous reading of the races power to suggest that it did not provide the federal government with the power to include Aboriginal peoples within programs and service delivery which were provided to the general community - instead it simply excluded the establishment of specialised laws and programs.

It must also be said that as a practical matter it is unlikely that - at least in the first half of the twentieth century - direct powers in the federal government to legislate for Indigenous peoples would have been of much benefit or resulted in a different situation to that which eventuated. This is clear by looking at the way that the Commonwealth administered the Northern Territory from 1911, with a system of control strikingly similar to other States at the time. The lack of protection in the Constitution, however, is something that has been of great significance in the recent past.

The movement for recognition of rights in the fifty or sixty years since federation can generally be summarised as one which focused on trying to achieve recognition of basic citizenship entitlements and the achievement of formal equality with the non-Indigenous population - that is, sameness of treatment.

One of the most important examples of this struggle for equality took place on the 150th anniversary of white settlement - Australia Day 1938. An event known as the Day of Mourning was held in Sydney by the Aborigines Progressive Association. Following this day, the Aborigines Progressive Association presented a '10 point plan' - perhaps the original ten point plan to Prime Minister Lyons on 13 January $1938^{2}$ which included the following demands:

- Commonwealth control of Aboriginal affairs;

- The establishment of a Commonwealth minister for Aboriginal affairs with cabinet rank - something which, incidentally, Minister Ruddock was the first to have achieved;

- The establishment of a Department of Aboriginal Affairs with Aboriginal representation;

- The aim of the department being to raise Indigenous peoples to 'full citizen status and civil equality with the whites in Australia', including through the provision of educational opportunities and equal entitlement to employment conditions, workers compensation and insurance, social security, the application of the same laws of intestacy and transmission of property as white people, to receive wages in cash, and to be able to purchase and own property;

- The application of the same marriage laws and housing entitlements as whites;

- Land settlement policies similar to the soldier settlers scheme to be introduced and financed; and

- Entitlements to maternity treatment and clinic instruction on baby welfare for Aboriginal mothers, among other things.

By 1948, however, there remained significant limitations on Indigenous peoples' freedoms, such as statutory bars on Aboriginal people voting in the NT, WA and the NT; laws which 
allowed removal to reserves in all states and territories except Tasmania; and the formal regulation of Indigenous employment in all states except NSW, South Australia and Tasmania.

At the same time at the federal level, Indigenous people who were under state control through reservations were not entitled to the range of social security benefits that existed at the time (age, invalid and widows pensions plus maternity allowances). Those who were exempt from the legislation also did not automatically have an entitlement to such benefits - it was then a matter of bureaucratic determination as to whether they were 'sufficiently advanced'. Should they be found to be so advanced, the benefits could then be paid to an institution rather than the individual concerned. New legislation in 1959 simplified the system but continued to deny to 'nomadic or primitive' Aborigines any entitlement to welfare. The last exclusionary provisions relating to welfare entitlements were removed in 1966.

I have exhausted the range of exclusions in some detail to highlight the extent of the control and exclusion that was exercised over Indigenous peoples lives. But I also emphasise how recently this approach was implemented, for we are talking about the living memory of many Indigenous people. The implications of this in terms of distrust of the broader community and the lack of skills to participate in the broader society on an equal footing cannot be forgotten or underestimated.

Most of the issues that have been used as examples - voting rights, social security entitlements etc - were remedied by the mid- to late 1960s, and it is also important to recognise this. We also have to reflect, however, on the entrenched disparity that their enforcement until the 1960s has had on Indigenous peoples. In my view, a significant factor that the broader community is still yet to embrace sufficiently is recognition that mere formal equality of treatment is not sufficient to undo generations of systemic discrimination and exclusion. This is a key issue for the treaty debate and I will talk about it again shortly.

Perhaps the culmination of this period was the 1967 Referendum. On 27 May 1967, 90.77 $\%$ of Australians agreed to the Referendum question to delete $s .127$ of the Constitution and remove the words which excluded Aborigines from the scope of the races power.

There had been a growing movement dating largely from the 1950s to alter the two provisions of the Constitution which excluded Indigenous peoples. The government of the day did not support the alteration of the races power as late as November 1965, when it put forward a bill which would see a referendum solely to repeal s.127. In support of this Prime Minister Menzies stated that the exclusion of Aborigines from s.51(26) - the races powers - was not discriminatory and indeed provided 'protection against discrimination by the Commonwealth Parliament'. It is perverse how this comment has come to be true through the passage of the amendments to the Native Title Act 1993, which occurred in 1998.

The 1967 Referendum is often seen as 'citizenship maker', but as I have stated this is not true - those reforms took place in the years before the referendum and in some instances - such as in Queensland - did not take place until the 1970s. In many ways this perception has arisen as Indigenous demands in the era that is seen as 'post-1967' is that they are more vocal and focused more squarely on the recognition of Indigenous rights - that is, on the recognition of the distinct status of Indigenous peoples whether through land rights, or calls for measures to protect and maintain culture. 
The Referendum is not such a clear point of delineation - such protest became prominent before this, from the Yirrkala bark petition and fight over mining in Arnhem land from 1963 to the Wave Hill walkoff in 1966 to the Freedom Ride of 1965. These events, right through to the creation of the tent embassy on the lawns of Parliament House on 26 January 1972 all contributed to a greater awareness of the desires of Indigenous peoples that extended beyond the provision of basic citizenship entitlements.

These protests motivated the passage of land rights legislation in the NT and racial discrimination legislation at the federal level by the mid-1970s. They also motivated a broader public movement for improving the treatment of Indigenous peoples - perhaps the most relevant of these movements, from the non-Indigenous side of things, was through the establishment of the Aboriginal Treaty Committee in 1979. This Committee published an ad in the National Times on 25 August 1979 titled 'We call for a treaty within Australia, between Australians'. It followed the call for a treaty by the National Aboriginal Congress earlier that year.

In their booklet, Its coming yet..., the Aboriginal Treaty Committee stated that: 'We believe there is a deep and wide concern among other Australians that our ownership of this land, as defined in the imported British law, should still be based solely upon force, without any documentary recognition of the rights or the quality and courage of those who were conquered. It is time to right this wrong. ${ }^{3}$

As Bill Stanner, a member of the Treaty Committee, had stated in 1973:

if you study carefully the words used in any one of our formal statements of policy towards [Indigenous people] you will not find anywhere two things said simply and clearly. The first is that we injured Aboriginal society and owe just recompense to its living members. The second is that what we will do now for them we will do in recognition of their natural rights as a distinct people, not in expression of our sufferance of them, of our acceptance of them, or of our acceptance of them if they will copy our ways. ${ }^{4}$

This is what the call for a treaty was about then. And I would submit it is what it is still about some 29 years after these words were spoken.

Accordingly, the Treaty Committee called for a treaty to be negotiated which covered the following issues:

- The protection of Aboriginal identity, languages, law and culture;

- National land rights legislation;

- Conditions governing mining and exploration of natural resources on Aboriginal land;

- Compensation for loss of traditional lands and for damage to those lands and traditional way of life; and

- Right of Aboriginals to control their own affairs and establish their own associations for this purpose. ${ }^{5}$

\footnotetext{
${ }^{3}$ Harris 1979: 1.

${ }^{4}$ W Stanner as quoted in Harris 1979: 74.

${ }^{5}$ As quoted in Harris 1979: 2.
} 
Concern was also expressed at the lack of priority given to Indigenous issues through minimal expenditure by the federal government - often being at a level of about 0.5 of one per cent of the federal budget.

The call for a treaty also had its antecedents in a call for recognition of the fact of dispossession and the provision of compensation by the first Aboriginal Senator, Neville Bonner, on 19 September 1974. The words that Senator Bonner spoke on that day have great resonance today. He said:

I do not decry the vast sums of money that have been spent by previous governments ... on indigenous affairs. I do not deny that the present government ... has instigated superbly beneficial programs to improve my fellow Aborigines' and Torres Strait Islanders' way of life within our broader Australian community. But it is truly to no avail, dignity-wise, when it is but an allocating of money for a disadvantaged people, because it is but a form of charity. We, the indigenous people, for far too long have been the recipients of charity - the charity of the government of the day; charity, with its modern day connotations implying a handout mentality.

What I am seeking is true and due entitlement for dispossession. Surely no one can deny that the aborigines and Torres Strait Islanders were dispossessed of what was theirs by right of inheritance ...

How do you value human suffering, the loss of human dignity, the loss of culture, the loss of a traditional way of life and the destruction of the Aboriginal society? ... You can put no monetary value on enforced disintegration. I am asking for compensation for this loss of land - earth - our entire being ... I am asking for compensation for our enforced disintegration. ${ }^{6}$

What Senator Bonner proposed was for a set amount to be set aside from the annual budget to become the true entitlement of the Indigenous peoples 'so that we may recapture our dignity and our pride as human beings'. This motion passed through the Senate six months after it had been proposed. Nothing more came of it.

Similarly, the 'deep and wide concern' of the broader community that had been identified by the Aboriginal Treaty Committee about the history of dispossession of Indigenous peoples did not lead to the irresistible campaign for a treaty that they had hoped for. And discussion of a treaty soon went off the national agenda until the signing of the Barunga statement by Prime Minister Hawke nearly ten years later in 1988.

This statement committed the government to:

- Work for a negotiated treaty with Aboriginal people;

- Provide the necessary support for Aboriginal people to carry out their own consultations and negotiations; and

- To stand ready to negotiate when the Aborigines presented their proposals to the government. ${ }^{7}$

\footnotetext{
${ }^{6}$ As quoted in Harris 1979: 6-8.

${ }^{7}$ The text of the Barunga statement is available at http://www.aiatsis.gov.au/lbry/dig_prgm/treaty/barunga.htm
} 
The end result was that somehow, by the end of the decade, treaty had again gone off the national agenda and been replaced by the seemingly less frightening process of reconciliation in 1991 .

In my view, it is no surprise that in the decade of fundamental change that was the nineties, treaty had again emerged at the end of the decade.

As I have noted in my recent Social Justice Reports, the period beginning with the reports of the Royal Commission into Aboriginal Deaths in Custody and the reconciliation process, have been a significant period of transformation in Australian history. ${ }^{8}$ From deaths in custody to the creation of ATSIC, to Mabo, ${ }^{9}$ the rejection of terra nullius and recognition of the ongoing connections of Indigenous cultures to land, to the Native Title Act, ${ }^{10}$ Indigenous Land Fund and Social Justice Package proposals, ${ }^{11}$ to the 1997 Bringing them home report, ${ }^{12}$ the foundational myths of settlement and the reality of the history of Indigenous-non-Indigenous relations have been exposed and recognised once and for all.

We have now reached a point from which there is no turning back. Non-Indigenous Australians have been exposed to a version of history which wasn't taught in school and which has brought into question - in the most confronting way - the fundamental basis of their relationships with Indigenous people. We cannot underestimate the significance or importance of this.

But such recognition does not of itself solve the problems that have emerged throughout this history. In short, this recognition has sent us into a no-man's land. As I stated in my Social Justice Report 2000, it has exposed the fundamental contradiction at the heart of Australian society. ${ }^{13}$ But what have we done, as a society, about this contradiction?

It is my firm belief that rather than acknowledging this contradiction, rather than acknowledging the harm, as a society we have simply put it into the too-hard basket with justifications about the level of 'uncertainty', the 'divisiveness' and the cost of addressing the issue.

And governments have gone to extraordinary, breathtaking lengths to maintain the status quo and prevent the leakage of any power back to Indigenous peoples.

We have seen the excision of the operation of Aboriginal heritage protection laws to allow development to go ahead at Hindmarsh Island (Hindmarsh Island Bridge Act 1997). In legal challenges to this action the federal government conceded that it believed that it was feasible that it could use the races power in the Constitution to introduce 'Nazi-style' laws, rather than that power being solely for laws which are purely beneficial in nature. Ultimately the Court did not resolve this issue, though it hinted strongly that this may indeed be the case.

We have seen the steadfast refusal of the federal government to comply with its human rights obligations by enforcing compliance of states and territories with such obligations by repealing racially discriminatory mandatory detention laws.

\footnotetext{
${ }^{8}$ Aboriginal and Torres Strait Islander Social Justice Commissioner 2000: 5-8.

${ }^{9}$ Mabo and Ors $v$ The State of Queensland (No 1) (1988) 166 CLR 18: Mabo and Ors v The State of Queensland (No 2) (1992) 175 CLR 1.

${ }^{10}$ Native Title Act 1993 (Cth).
}

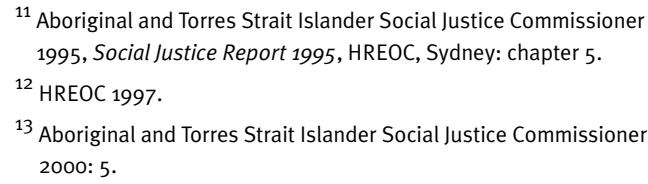

${ }^{11}$ Aboriginal and Torres Strait Islander Social Justice Commissioner 1995, Social Justice Report 1995, HREOC, Sydney: chapter 5.

12 HREOC 1997.

${ }^{13}$ Aboriginal and Torres Strait Islander Social Justice Commissioner 2000: 5 . 
We have seen the rejection of an holistic response to the stolen generations through the partial implementation of the recommendations of Bringing them home, the refusal to make reparation and the failure to engage in symbolic gestures of apology.

We have seen marginal improvements in the ratio of deaths in custody and increasing levels of over-representation, despite the constant commitment of governments to address these issues as matters of urgency.

And we have seen the introduction of racially discriminatory amendments to native title laws which have taken a system of checks and balances and re-oriented it away from providing lasting opportunities for Indigenous peoples.

As I said in my Native Title Report 2001, the native title system now aims to restrict rather than maximise the benefits to Indigenous peoples:

As an embodiment of social relations, the native title system places Indigenous interests at a lower level than non-Indigenous interests, every time. As an embodiment of economic relations, the native title system removes Indigenous people's effective control over their only asset: exclusive rights to land and sea country. As an embodiment of political relations, native title fails to recognise traditional decisionmaking structures. ${ }^{14}$

And I must say that I do not share any optimism that agreement-making processes under the 1993 Native Title Act offer a de facto treaty making process. This is too simplistic and fundamentally ignores the point that the native title system as structured is one that is not based on equality and non-discrimination. It does not facilitate the full and effective participation of Indigenous people. It is not a respectful system.

Only when the native title system does provide real equality of opportunity - ranging from adequate, and equitable, resourcing of native title representatives through to the ability to negotiate over economic and development opportunities, through to processes which facilitate Indigenous governance rather than imposed management structures - can it aim to fulfill this broader role.

But to return to an issue I raised earlier, perhaps the greatest problem that we still face is the response to the ongoing, entrenched disadvantage of Indigenous people. So-called 'practical reconciliation' is a cruel illusion of equality, which in fact amounts to a perpetuation of the marginalisation and disadvantage of the past.

I have explored these issues in great detail in my Social Justice Report 2000, but to give a brief example - human rights principles relating to non-discrimination on the basis of race in the provision of economic, social and cultural rights - such as the rights to an adequate standard of living, to a minimum standard of health and education for example - provide that governments must take steps towards the 'progressive realization' of such rights. ${ }^{15}$ They must identify that a particular issue is one of great priority and seek to address it with urgency and in such a way that the inequality gap is progressively reduced, within the shortest possible timeframe.

\footnotetext{
${ }^{14}$ Aboriginal and Torres Strait Islander Social Justice Commissioner 2001: 2

${ }^{15}$ See Aboriginal and Torres Strait Islander Social Justice Commissioner 2000: 24-5, and 2002: chapter 4.
} 
The level of Indigenous marginalisation and disadvantage, and the enormous gap that exists compared to the non-Indigenous population on all measures of economic and social status indicate that addressing Indigenous marginalisation is unquestionably an issue of such magnitude. Yet where are solid commitments to reducing the gap, within the shortest possible timeframe? What are the targets? Where is the accountability?

Or as a member of the Committee on the Elimination of Racial Discrimination put it, why in a modern industrialised nation does less than $2 \%$ of the population continue to suffer such dire economic circumstances? ${ }^{? 6}$

The answer to each of these questions suggests that current progress is unacceptable. There needs to be a deeper appreciation, and an unqualified acceptance, of the simple fact that Indigenous marginalisation is historically derived and the result of systemic racism in this country. It also requires an unqualified commitment to redressing it and to achieving genuine equality with the rest of society. My Social Justice Report 2000 provided 14 recommendations towards achieving this goal. ${ }^{17}$ It also examines the social cost approach proposed by the Canadian Royal Commission into Aboriginal Peoples and the Closing the gaps approach adopted by the New Zealand government to similar issues. ${ }^{18}$

This is an issue that is legitimately the subject of negotiation with and commitments to Indigenous people by Australian governments. And it is a matter of fundamental importance for treaty.

I do not make these comments lightly. Nothing less than strong leadership and commitment by governments, and within our own communities, will resolve the often desperate conditions experienced by our peoples. But I want to draw together the two main themes of this presentation.

There are two types of rights that must be recognised for Indigenous peoples to be able to live equally in Australia. Those that are enjoyed by every Australian, including Aboriginal people, commonly referred to as citizenship rights; and those that are inherent to Indigenous people only.

Australia has had almost a decade to establish a fair and just system to allow the benefits of inherent rights to be enjoyed by Indigenous people. This has not eventuated.

Formal equality on its own is not enough. As a tool of social change it is inadequate and, indeed, entrenches the inequality that already exists. The problem is not that Aboriginal people were given equal rights and treated like everyone else. The problem is that these are the only rights that Aboriginal people were given. This type of formal equality is not enough to restore Aboriginal people to their rightful place as the first peoples of this country. We need to go further with rights. We need to adopt a rights approach that does have the capacity to transform social, economic and political relations in Australia.

I have, in my previous annual reports advocated two types of measures, based on rights, which have this capacity. ${ }^{19}$ First, measures known as special measures, aimed at achieving equality, rather than assuming it; and second, the full recognition of Indigenous people's inherent rights, in particular native title.

\footnotetext{
${ }^{16}$ Aboriginal and Torres Strait Social Justice Commissioner 2000: 58.

${ }^{18}$ Aboriginal and Torres Strait Social Justice Commissioner 2000: 92.

${ }^{17}$ Aboriginal and Torres Strait Social Justice Commissioner 2000: 130-2.

${ }^{19}$ William Jonas was Aboriginal and Torres Strait Islander Social Justice Commissioner from 1999-2004
} 
A combined approach, utilising these two types of rights, has not been adopted by any Australian government as a way of addressing the disadvantage it is designed to transform. When an opportunity did arise to recognise inherent rights through native title it was immediately encased in a legal armature that gave it no room to deliver real outcomes. Its capacity to provide economic opportunities for Indigenous people, to provide equal respect for Indigenous culture, to provide governance structures for Aboriginal communities has been severely limited through the Native Title Act and the common law. The proposal to implement special measures to overcome the destructive cultural, social and economic impact of dispossession with the full participation and consent of Indigenous people through the Social Justice Package was never pursued by any government.

For the third time in 30 years, Indigenous people have begun to look to a treaty as an allencompassing way of addressing the deep contradictions that exist in our society. It will be difficult. But it will ultimately be easier, and I believe less costly, than the maintenance of the status quo which is clearly unsustainable. Let's get it right this time.

\section{Acknowledgments}

The author wishes to acknowledge the assistance of Dr Darren Dick in the preparation of this article

\section{References}

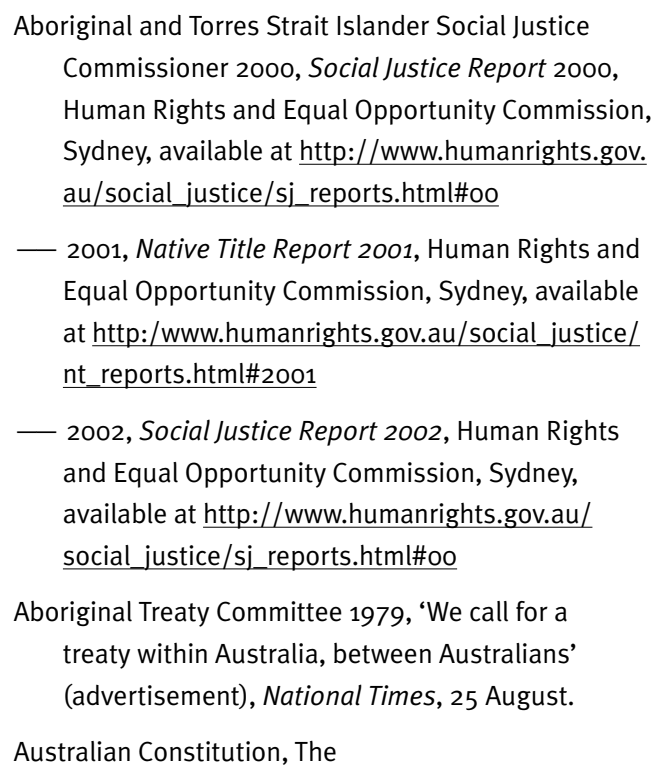

Barunga statement, 1988, available at http://www. aiatsis.gov.au/lbry/dig_prgm/treaty/barunga.htm

\author{
Chesterman, J and B Galligan 1998, Citizens without \\ rights - Aborigines and Australian citizenship, \\ Cambridge University Press, Cambridge. \\ Harris, Stewart 1979, 'Its coming yet ... 'An Aboriginal \\ treaty within Australia between Australians, The \\ Aboriginal Treaty Committee, Canberra. \\ Human Rights and Equal Opportunity Commission \\ 1997, Bringing them home, HREOC, Sydney. \\ Patten, J (ed) 1938, The Australian Call - The Voice of \\ the Aborigine, April, issue 1, 1.

\section{Legislation} \\ Native Title Act 1993 (Cth). \\ Native Title 1998
}

